\title{
A position statement and practical guide to the use of particulate filtering facepiece respirators (N95, FFP2 or equivalent) for South African health workers exposed to respiratory pathogens including Mycobacterium tuberculosis and SARS-CoV-2
}

K Dheda, ${ }^{1,2}$ MB BCh, FCP (SA), FCCP, PhD, FRCP (Lond); S Charalambous, ${ }^{3,4}$ MB BCh, MSc, PhD; A S Karat, ${ }^{5} \mathrm{MRCP}(\mathrm{UK}), \mathrm{PhD}$; A von Delft, ${ }^{6,7} \mathrm{MB}$ ChB; U G Lalloo, ${ }^{8,9} \mathrm{MB}$ ChB, FCPS (SA), FCCP, MD, DoH; R van Zyl Smit, ${ }^{10} \mathrm{MB}$ ChB, MRCP, FCP, MMed, PhD; R Perumal, ${ }^{1}$ MB ChB, MMed, MPhil, MPH, FCP (SA), Cert Pulm (SA); B W Allwood, ${ }^{11}$ MB ChB, FCP (SA), Cert Pulm (SA), PhD; A Esmail, ${ }^{12} \mathrm{MD}$, FCP (SA); M L Wong, ${ }^{13} \mathrm{MB}$ BCh, DCH (SA), FCP (SA), FCCP, FRCP (Lond);

A G Duse, ${ }^{14} \mathrm{MB}$ BCh, MScMed, MMed, FCPath (SA) Micro, DTM\&H; G Richards, ${ }^{15} \mathrm{MB}$ ChB, PhD;

C Feldman, ${ }^{16} \mathrm{MB}$ BCh, DSc, PhD, FRCP, FCP (SA); M Mer, ${ }^{17} \mathrm{MB}$ BCh, Dip PEC (SA), FCP (SA), MMed (Int Med), Cert Critical Care (SA), FRCP (Lond), FCCP, PhD; K Nyamande, ${ }^{18} \mathrm{MB}$ ChB, FCP (SA), Cert Pulm (SA), FCCP, PhD;

U Lalla, ${ }^{11} \mathrm{MB}$ ChB, FCP (SA), MMed (Int), Cert Crit Care (SA) Phys;

C F N Koegelenberg, ${ }^{11}$ MBChB, MMed (Int), FCP (SA), FRCP (UK), Cert Pulm (SA), PhD; F Venter, ${ }^{19}$ MB ChB, FCP (SA), PhD;

H Dawood, ${ }^{20} \mathrm{MB}$ BCh, FCP (SA), MSc, LLM, DTM\&H; S Adams, ${ }^{21}$ MB ChB, MMed, PhD, FCPHM (SA);

N A B Ntusi, ${ }^{22}$ MB ChB, FCP (SA), DPhil, MD; H-M van der Westhuizen, ${ }^{7,23}$ MB ChB; M-Y S Moosa, ${ }^{24,25}$ MB ChB, FCP (SA), PhD; N A Martinson, ${ }^{26,27} \mathrm{MB}$ BCh, DCH, MFGP, MPH; H Moultrie, ${ }^{28,29} \mathrm{MB}$ BCh, MSc; J Nel, ${ }^{30} \mathrm{MB}$ ChB, FCP (SA), Cert ID (SA), DTM\&H; H Hausler, ${ }^{31}$ MD CM, MPH, PhD; W Preiser, ${ }^{32}$ Dr Med, Dr Med Habil, DTM\&H (LSHTM), MRCPath (UK), MASSAf;

L Lasersohn, ${ }^{33,34,35}$ MB BCh, DA (SA), FCA (SA), Cert Crit Care (SA); H J Zar, ${ }^{36}$ MB BCh, FCPaeds, FRCP (Edinburgh), PhD;

G J Churchyard, ${ }^{3,437}$ MB BCh, FCP (SA), MMed, PhD

${ }^{1}$ Centre for Lung Infection and Immunity, Division of Pulmonology, Department of Medicine and UCT Lung Institute and South African MRC/UCT Centre for the Study of Antimicrobial Resistance, University of Cape Town, South Africa

${ }^{2}$ Faculty of Infectious and Tropical Diseases, Department of Immunology and Infection, London School of Hygiene and Tropical Medicine, London, United Kingdom

${ }^{3}$ The Aurum Institute, Johannesburg, South Africa

${ }^{4}$ School of Public Health, University of the Witwatersrand, Johannesburg, South Africa

${ }^{5}$ TB Centre, London School of Hygiene and Tropical Medicine, London, United Kingdom

${ }^{6}$ School of Public Health and Family Medicine, University of Cape Town, South Africa

${ }^{7}$ TB Proof, South Africa

${ }^{8}$ Gateway Private Hospital Medical Centre, Umhlanga Ridge, South Africa

${ }^{9}$ Durban International Clinical Research Site, Durban, South Africa

${ }^{10}$ Division of Pulmonology and Department of Medicine, University of Cape Town and Groote Schuur Hospital, Cape Town, South Africa

${ }^{11}$ Division of Pulmonology, Department of Medicine, Stellenbosch University and Tygerberg Hospital, Cape Town, South Africa

${ }^{12}$ Clinical Trials Unit, University of Cape Town Lung Institute, South Africa

${ }^{13}$ Division of Pulmonology, Department of Medicine, School of Clinical Medicine, Faculty of Health Sciences, University of the Witwatersrand, Johannesburg, South Africa

${ }^{14}$ Clinical Microbiology \& Infectious Diseases, School of Pathology of the NHLS \& University of the Witwatersrand, Johannesburg, South Africa

${ }^{15}$ Department of Critical Care, Faculty of Health Sciences, University of the Witwatersrand, Johannesburg, South Africa

${ }^{16}$ Department of Internal Medicine, School of Clinical Medicine, Faculty of Health Sciences, University of the Witwatersrand, Johannesburg, South Africa

${ }^{17}$ Department of Medicine, Divisions of Pulmonology and Critical Care, Charlotte Maxeke Johannesburg Academic Hospital and Faculty of Health Sciences,

University of the Witwatersrand, Johannesburg, South Africa

${ }^{18}$ Department of Pulmonology, Nelson R Mandela School of Medicine, College of Health Sciences, University of KwaZulu Natal, Durban, South Africa

${ }^{19}$ Ezintsha, Faculty of Health Sciences, University of the Witwatersrand, Johannesburg, South Africa

${ }^{20}$ Greys Hospital, Pietermaritzburg, South Africa

${ }^{21}$ Division of Occupational Medicine, School of Public Health and Family Medicine, University of Cape Town, South Africa

${ }^{22}$ Division of Cardiology, Department of Medicine, University of Cape Town and Groote Schuur Hospital, Cape Town, South Africa

${ }^{23}$ Nuffield Department of Primary Care Health Sciences, University of Oxford, United Kingdom

${ }^{24}$ Department of Infectious Diseases, Division of Internal Medicine, Nelson R Mandela School of Medicine, University of KwaZulu-Natal, Durban, South Africa

${ }^{25}$ Southern African HIV Clinicians Society

${ }^{26}$ Perinatal HIV Research Unit (PHRU), University of the Witwatersrand, Johannesburg, South Africa

${ }^{27}$ Johns Hopkins University Center for TB Research, Baltimore, USA

${ }^{28}$ National Institute for Communicable Diseases, Division of the National Health Laboratory Service, Johannesburg, South Africa

${ }^{29}$ Clinical Microbiology \& Infectious Diseases, School of Pathology, Faculty of Health Sciences, University of the Witwatersrand, Johannesburg, South Africa 
${ }^{30}$ Division of Infectious Diseases, Department of Medicine, University of the Witwatersrand, Johannesburg, South Africa

${ }^{31}$ TB HIV Care, Cape Town, South Africa

${ }^{32}$ Division of Medical Virology, Faculty of Medicine and Health Sciences, Stellenbosch University and National Health Laboratory Service Tygerberg, Cape Town, South Africa

${ }^{33}$ South African Society of Anaesthesiologists

${ }^{34}$ Department of Anaesthesia, Faculty of Health Sciences, University of the Witwatersrand, Johannesburg, South Africa

${ }^{35}$ Division of Critical Care, Chris Hani Baragwanath Hospital and University of the Witwatersrand, Johannesburg, South Africa

${ }^{36}$ Department of Paediatrics \& Child Health, Red Cross Children's Hospital and SAMRC Unit on Child and Adolescent Health, University of Cape Town, South Africa

${ }^{37}$ Department of Medicine, Vanderbilt University, Nashville, Tennessee, USA

Declaration. A position statement endorsed by the South African Thoracic Society, Infection Control Society of South Africa, South African Society of Anaesthesiologists, Critical Care Society of Southern Africa, South African Medical Association, South African HIV Clinicians Society, Infectious Diseases Society of South Africa, South African Heart Association, South African Society of Occupational Medicine, TB Proof, and Free of TB.

Corresponding author: KDheda (keertan.dheda@uct.ac.za)

\section{Summary}

Severe acute respiratory syndrome coronavirus-2 (SARS-CoV-2) is transmitted mainly by aerosol in particles $<10 \mu \mathrm{m}$ that can remain suspended for hours before being inhaled. Because particulate filtering facepiece respirators ('respirators'; e.g. N95 masks) are more effective than surgical masks against bio-aerosols, many international organisations now recommend that health workers (HWs) wear a respirator when caring for individuals who may have COVID-19. In South Africa (SA), however, surgical masks are still recommended for the routine care of individuals with possible or confirmed COVID-19, with respirators reserved for so-called aerosol-generating procedures. In contrast, SA guidelines do recommend respirators for routine care of individuals with possible or confirmed tuberculosis (TB), which is also transmitted via aerosol. In health facilities in SA, distinguishing between TB and COVID-19 is challenging without examination and investigation, both of which may expose HWs to potentially infectious individuals. Symptom-based triage has limited utility in defining risk. Indeed, significant proportions of individuals with COVID-19 and/or pulmonary TB may not have symptoms and/or test negative. The prevalence of undiagnosed respiratory disease is therefore likely significant in many general clinical areas (e.g. waiting areas). Moreover, a proportion of HWs are HIV-positive and are at increased risk of severe COVID-19 and death.

\section{Recommendations}

Sustained improvements in infection prevention and control (IPC) require reorganisation of systems to prioritise HW and patient safety. While this will take time, it is unacceptable to leave HWs exposed until such changes are made. We propose that the SA health system adopts a target of 'zero harm', aiming to eliminate transmission of respiratory pathogens to all individuals in every healthcare setting.

Accordingly, we recommend:

1. the use of respirators by all staff (clinical and non-clinical) during activities that involve contact or sharing air in indoor spaces with individuals who: ( $i$ ) have not yet been clinically evaluated; or (ii) are thought or known to have TB and/or COVID-19 or other potentially harmful respiratory infections;

2. the use of respirators that meet national and international manufacturing standards;

3. evaluation of all respirators, at the least, by qualitative fit testing; and

4. the use of respirators as part of a 'package of care' in line with international IPC recommendations.

We recognise that this will be challenging, not least due to global and national shortages of personal protective equipment (PPE). SA national policy around respiratory protective equipment enables a robust framework for manufacture and quality control and has been supported by local manufacturers and the Department of Trade, Industry and Competition. Respirator manufacturers should explore adaptations to improve comfort and reduce barriers to communication. Structural changes are needed urgently to improve the safety of health facilities: persistent advocacy and research around potential systems change remain essential.

Keywords. tuberculosis; COVID-19; SARS-CoV-2; transmission; healthcare worker; occupational; nosocomial.

Afr J Thoracic Crit Care Med 2021;27(4):177-186. https://doi.org/10.7196/AJTCCM.2021.v27i4.173

Almost 2.5 million South Africans have tested positive for severe acute respiratory syndrome coronavirus-2 (SARS-CoV-2) since March 2020, and >90 000 have died in hospitals from COVID-19. ${ }^{[1]}$
Although SARS-CoV-2 was initially thought to spread predominantly through droplet or direct contact, there is strong evidence that aerosol-based transmission is likely the dominant route of spread. ${ }^{[2]}$ 
This is especially important in the light of the circulation (at the time of writing) of the Delta variant, which is more transmissible than the original virus or Beta variant. ${ }^{[3]}$ Clinically distinguishing people with COVID-19 from those with other respiratory infections is impossible without testing. This is because many people infected with SARS$\mathrm{CoV}-2$ are asymptomatic (estimates of asymptomatic proportions vary widely from $<20$ to $>90 \%$ ), ${ }^{[4,5]}$ and because many respiratory symptoms experienced are often nonspecific ${ }^{[6]}$ Frontline health workers (HWs) are highly exposed and at high risk of infection, as shown by the thousands who have been infected, developed illness, and died. ${ }^{[7]}$

HWs in high tuberculosis (TB) burden countries are already at high risk of TB infection and disease.$^{[8-11]}$ Despite significant progress, TB incidence in South Africa (SA) remains high at over 600 per 100000 population (around 360000 new cases per year), and it has consistently been the country's leading cause of death, responsible for $\sim 60000$ deaths every year. ${ }^{[12]}$ Management of a respiratory pandemic is more complex in high TB burden countries such as SA. In addition to previous or current $\mathrm{TB}$, individuals seeking care often have a history of one or more of HIV, tobacco smoking, biomass fuel exposure, outdoor air pollution, or exposure to mine dust containing silica, which considerably expands the differential diagnosis in those presenting with respiratory symptoms. ${ }^{[13-16]}$ Presentations and risk factors can be difficult to differentiate without additional time and investigation, both of which can increase the likelihood and duration of HW exposure to infectious individuals. Current or previous TB may also place people at increased risk of developing COVID-19, ${ }^{[17]}$ and having COVID-19 may increase the risk of TB, though reliable data are not yet available.

International guidelines recommend that HWs should be wearing N95 or equivalent particulate filtering facepiece respirators ('respirators') for routine care of individuals with possible TB or COVID-19, although World Health Organization [WHO] COVID-19 guidelines are not entirely consistent. ${ }^{[18,19]}$ At the time of writing, however, SA COVID-19 guidelines state that this level of protection is needed only for 'aerosolgenerating' procedures (AGPs), such as intubation and bronchoscopy. ${ }^{[19-21]}$ Recent studies suggest that coughing - common in both TB and COVID-19 pneumonitis - may produce as much (or more) aerosol than some AGPs. ${ }^{[22-24]}$ There is also strong evidence that, like Mycobacterium tuberculosis $(M t b),{ }^{[2,25]}$ SARS-CoV-2 is also transmitted by aerosol. The data to support this are wide-ranging, and include outbreak investigations, ${ }^{[2]}$ experiments showing virus viability in aerosols for up to 3 hours, ${ }^{[26]}$ detection of viable virus in air samples from COVID-19 infected persons and animals, ${ }^{[27-29]}$ and identification of SARS-CoV-2 in air filters and ducts. ${ }^{[30]}$ In other studies, activities like speaking, shouting, and singing have been shown to produce substantial amounts of infectious aerosol, and the use of high-flow oxygen may also increase aerosol propagation. ${ }^{[31,32]}$ The definition of an AGP in SA guidelines is therefore overly restrictive ${ }^{[21]}$ and there is a pressing need to ensure that HWs are adequately protected from both $M t b$ and SARS-CoV-2.

In this position statement, we build the case for national policies to support more widespread and consistent use of respirators by HWs in high-TB-burden countries such as SA, both during the ongoing COVID-19 pandemic and beyond. We make specific recommendations for situations in which respirators should be worn by HWs in SA and discuss some of the additional efforts needed to sustain this policy.

\section{Making the argument}

\section{Health workers are left unprotected}

Effective implementation of infection prevention and control (IPC) in healthcare facilities is important to avoid 'institutional amplification' of epidemics, ${ }^{[33-35]}$ to protect the people who attend and work there, and to preserve the health workforce - a critical issue at all times, and more so during a pandemic. TB in HWs is a persistent problem: numerous studies over 30 years have shown that HWs in high-TB-burden countries are more likely than the general population to develop both latent TB and active TB disease, largely because of occupational exposure..$^{[8,9,36-39]}$ Many HWs may have underlying vulnerability to severe disease and require extra protection. ${ }^{[40,41]}$ In addition to the risk to HWs themselves, there are also risks of transmission to their families, vulnerable household members, and patients. The thousands of HWs who have developed and died from COVID-19 in the last 18 months clearly demonstrate both the risks faced by HWs and the insufficient priority given to HW safety. ${ }^{[7,42-45]}$

HWs, like all other SA workers, have a right to a healthy and safe working environment. ${ }^{[46]} \mathrm{HW}$ s worldwide have paid a disproportionate price for governments' and health systems' lack of foresight, lack of preparation, and underinvestment in pandemic preparedness. ${ }^{[4]}$ This has manifested, among other things, as inadequate or insufficient personal protective equipment (PPE) for frontline and other staff. ${ }^{[48,49]}$ Indeed, it was shown recently that none of the tested 'KN95' respirators evaluated in SA met stipulated safety standards for HW protection. ${ }^{[50]}$ We echo calls by other authors for urgent research, funding, and prioritisation of IPC and HW protection ${ }^{[51]}$ and for more comprehensive approaches to occupational health. ${ }^{[52,53]}$ Though we recognise that systemic changes will take time to enact, it is unacceptable that HWs remain at risk until such changes are made.

\section{On the frontline, it is impossible to differentiate between TB, SARS-CoV2 and other infections}

It is near impossible to make a specific diagnosis of TB, COVID-19, or other respiratory disease in most SA healthcare facilities without detailed clinical assessment and laboratory investigation. This usually takes at least $24-72$ hours (the turnaround time of most diagnostic tests). Clinical diagnosis is difficult because there are overlapping risk factors, a multitude of possible presentations (including non-specific symptoms such as fever or cough), and often more than one infection. ${ }^{[13-15,17,54,55]}$ If assessing HWs are not adequately protected, this can be a major opportunity for transmission to occur. Transmission of SARS-CoV-2 by asymptomatic individuals has been widely documented, ${ }^{[6]}$ and the burden of 'subclinical' $\mathrm{TB}^{[56]}$ in $\mathrm{SA}$ is increasingly evident. The recent national TB prevalence survey found that around half of the people in the community with confirmed pulmonary TB did not have symptoms suggestive of $\mathrm{TB}^{[57]}$ and a recent study in KwaZulu-Natal showed similar findings among adults attending primary healthcare (PHC) clinics. ${ }^{[58]}$

Symptom screening cannot differentiate between TB and other respiratory infections. TB can often present as acute pneumonia or acute lower respiratory tract infection (LRTI), and Mtb may be among the most common pathogens isolated in this context in Asian and African settings (reviewed in detail in a recent article). ${ }^{[54]}$ In a large study from SA ( $n=2500$ patients), a symptom duration threshold of $>14$ days was unable to distinguish between TB and other respiratory pathogens, and in those with LRTI of $<14$ days duration, TB was 
the microbiologically-proven diagnosis in $\sim 18 \%$ of patients. ${ }^{[59]}$ This figure is remarkable, considering that in patients with acute LRTI, a microbiological diagnosis is made in only $~ 50 \%$ of cases.

Triage based on symptom screening is challenging to perform consistently and has been shown to be sub-optimally implemented at PHC clinics across the country. ${ }^{[60,61]}$ In addition, adults accompanying children or other vulnerable individuals may not be screened and may be undetected sources of $M t b$ or SARS-CoV-2. This means that potentially infectious individuals with undetected disease (with or without symptoms) may remain in general patient streams in perceived 'lower-risk' areas, with subsequent inappropriate use of less effective PPE by HWs.

As discussed below, current guidance recommends use of different PPE for different 'types' of patients (e.g. respirators only when in contact with individuals with 'possible' or 'known' TB or COVID-19). As we have emphasised, however, it is almost impossible to estimate who is likely to have TB or COVID-19 (or another respiratory infection, such as influenza or bacterial or fungal pneumonia). It is also difficult to reliably estimate the risk of transmission in any given space at any given time without information on infectiousness, ventilation, occupancy of rooms, and duration of exposure. ${ }^{[62]}$ It is therefore unrealistic to expect individual HWs to make repeated assessments of risk during the course of a working day and adjust their PPE accordingly, particularly at a time when the health system is under pressure. ${ }^{[63,64]}$

SARS-CoV-2 and $M t b$ are transmitted by aerosol: particulate filtering facepiece respirators offer better protection

Person-to-person transmission of SARS-CoV-2 is currently understood to occur predominantly by two routes. First, via larger respiratory droplets $(>10 \mu \mathrm{m})$, which fall rapidly to the ground or onto surfaces - droplets of size $10 \mu \mathrm{m}$ and $100 \mu \mathrm{m}$ take 10 minutes and $\sim 6$ seconds, respectively, to fall to the ground. ${ }^{[65]}$ Such droplets may be inhaled or deposited into the nasopharynx or directly inoculated onto mucous membranes (eyes, mouth, upper pharynx) or the skin, with subsequent person-to-person transfer via direct contact or infected fomites. Second, via aerosol: particles produced through coughing, speech, singing, and AGPs, which after desiccation are usually up to $10 \mu \mathrm{m}$ in diameter, can remain suspended in the air for several hours, and may be inhaled into the lungs (small airways and alveoli) of an exposed person. ${ }^{[25,66-69]}$ The second route, sometimes referred to as airborne transmission, is also the main route of transmission of the measles virus and $M t b{ }^{[62,70]}$ However, is important to note that terminology (airborne v. aerosol v. respiratory droplets) is not standardised or well defined, and thus airborne spread is likely to be due to production of a continuum of virus-containing droplet sizes that may be deposited in the upper and/or lower respiratory tract of susceptible individuals. ${ }^{[25]}$

Early in the pandemic, SARS-CoV-2 was thought to be transmissible only via large droplets/fomites, and precautions therefore centred on restricting close contact, cleaning surfaces, and handwashing. ${ }^{[71,72]}$ However, research on aerosolisation has shown that respiratory particle sizes vary widely, and that smaller particles $(<5 \mu \mathrm{m})$ are more likely to contain pathogen. ${ }^{[25]}$ The high likelihood of aerosol transmission of SARS-CoV-2 $2^{[2,73-75]}$ has now been acknowledged by WHO and the United States Centers for Disease Control and Prevention (US CDC), which recently made recommendations around improving ventilation of indoor spaces as part of coronavirus-related IPC..$^{[76,77]}$ Ventilation is important for mitigating aerosol transmission: increasing the number of air

Table 1. South African and international recommendations (at the time of writing) for use of masks and respirators by health workers*

\begin{tabular}{|c|c|c|c|c|c|}
\hline \multirow[b]{2}{*}{ Source } & \multirow[b]{2}{*}{ Scope } & \multicolumn{2}{|r|}{ TB } & \multicolumn{2}{|c|}{ COVID-19 } \\
\hline & & Routine care ${ }^{\#}$ & $\mathrm{AGPs}^{\dagger}$ & Routine care ${ }^{\#}$ & $\mathrm{AGPs}^{\dagger}$ \\
\hline $\mathrm{SA} \mathrm{DoH} / \mathrm{NICD}^{[21,87]}$ & SA & N95 respirator & N95 respirator & Surgical mask & N95 respirator \\
\hline $\mathrm{WHO}^{[19,20]}$ & Global & $\begin{array}{l}\text { Particulate respirator } \\
\text { (high TB burden } \\
\text { settings) }{ }^{\ddagger}\end{array}$ & Particulate respirator & $\begin{array}{l}\text { N95/FFP2/FFP3 } \\
\text { respirator }\end{array}$ & $\begin{array}{l}\text { N95/FFP2/FFP3 } \\
\text { respirator }\end{array}$ \\
\hline $\mathrm{US} \mathrm{CDC}^{[90,91]}$ & USA & $\begin{array}{l}\text { N95 respirator } \\
\text { (at least) }\end{array}$ & $\begin{array}{l}\text { N95 respirator at least } \\
\text { Consider elastomeric } \\
\text { full-facepiece respirator or } \\
\text { PAPR }\end{array}$ & $\begin{array}{l}\text { N95 or equivalent or } \\
\text { higher-level respirator }\end{array}$ & $\begin{array}{l}\text { N95 respirator or } \\
\text { respirators that offer } \\
\text { a higher level of } \\
\text { protection }\end{array}$ \\
\hline $\mathrm{PHE}^{[85]} / \mathrm{NICE}^{[92]}$ & $\begin{array}{l}\text { England/ } \\
\text { United } \\
\text { Kingdom }\end{array}$ & FFP2 respirator & FFP2 or FFP3 respirator & $\begin{array}{l}\text { Fluid-resistant surgical } \\
\text { face mask (Type IIR) }\end{array}$ & $\begin{array}{l}\text { FFP3 respirator or } \\
\text { hood }\end{array}$ \\
\hline $\mathrm{ECDC}^{[93,94]}$ & Europe & Respirator & Respirator & Respirator & Respirator \\
\hline India MoHFW ${ }^{[95,96]}$ & India & N95 respirator & N95 respirator & N95 respirator ${ }^{\S}$ & N95 respirator \\
\hline \multicolumn{6}{|c|}{ 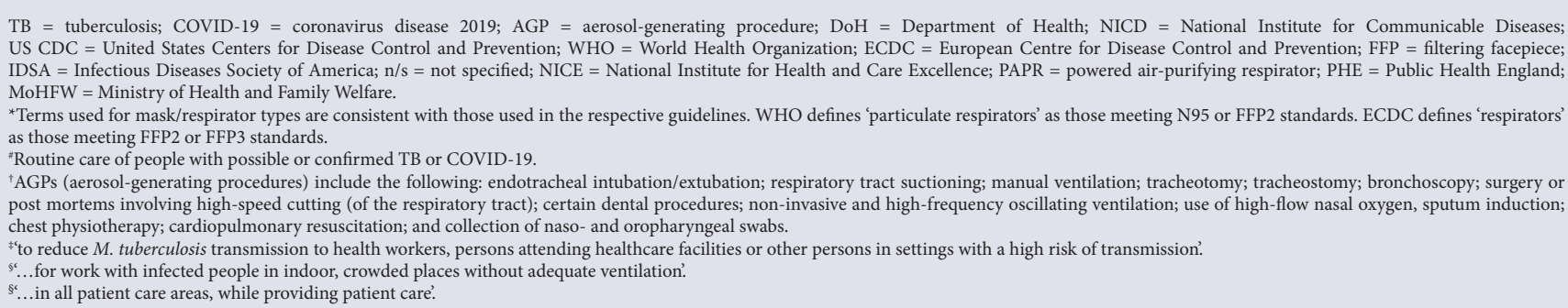 } \\
\hline
\end{tabular}


changes per hour means that suspended particles are more likely to be removed before they can be inhaled. ${ }^{[78,79]}$ Ten cogent reasons including underlying evidence as to why aerosol-based transmission is an important and co-dominant route of SARS-CoV-2 transmission were recently elegantly summarised in the Lancet..$^{[2]}$

The evidence around the relative efficacy of masks and respirators against aerosols is also reasonably clear. In laboratory studies, respirators (filtering facepiece (FFP) 2 or FFP3) were shown to be 16 - 108 times more effective than fluid-repellent surgical masks (FRSMs) in filtering aerosolised sodium chloride. ${ }^{[80]}$ Clinical studies are less definitive, in part because of variation in methodologies and definitions of exposure, and issues with the power of the studies. At least two studies, however, have shown statistically important reductions in risk with use of quality respirators compared with surgical masks, particularly when used continuously (as opposed to 'targeted' use) and when individuals were exposed to clinical respiratory illness. ${ }^{[80-84]}$

\section{Current South African guidance is at odds with international recommendations}

Table 1 summarises SA and global guidance around respirator use for personal protection against $M t b$ and SARS-CoV-2. The majority of national and international bodies (other than Public Health England $)^{[85]}$ recommend the use of respirators for routine care of individuals with possible or confirmed COVID-19 or TB. SA, at present, recommends an N95 respirator for care of individuals with possible or confirmed TB (in line with 2001 legislation around hazardous biological agents), ${ }^{[86]}$ but only a surgical mask for routine care of individuals with possible or confirmed COVID-19, which is at odds with recent employment legislation. ${ }^{[21,87-89]}$ This does not offer individuals protection against aerosol transmission of SARS-CoV-2. Importantly, this also requires HWs to differentiate between those who may have TB and those who may have COVID-19, which, as outlined above, may be impossible to do without risking exposure.

In summary (and sidestepping controversies about whether surgical masks or respirators are essential for protection against SARS-CoV-2), the high risk of HW exposure to and infection with $M t b$ and inability to differentiate TB from other acute LRTIs mandates the consistent use of respirators by HWs in high TB burden settings. It is impractical and not clinically meaningful to provide pathogen-specific guidance on masking. We have therefore provided guidance below in the context of routine exposure to acute respiratory infections.

\section{Recommendations}

Zero transmission, zero harm: Our recommendations for the widespread consistent use of particulate respirators in high TB burden settings

We propose that the health system should aim for a target of 'zero transmission, zero harm': a position that builds on the precautionary principle ${ }^{[97]}$ and the foundational ethical value of 'do no harm' to suggest that the health system's duty of care extends beyond patients to include its workforce. The principle of 'zero harm' has been used most widely to refer to efforts to improve patient safety, ${ }^{[98]}$ but here we use the term specifically around disease transmission. It is unacceptable that any person should be infected with $M t b$ or SARS-CoV-2 because of exposure in a healthcare facility, and the health system should aim to eliminate transmission in all healthcare settings. Clearly, this will require prioritisation and significant long-term investment in a range of IPC measures. These include consideration of building design, ventilation, ultraviolet germicidal irradiation (UVGI) systems, and organisation of services to reduce overcrowding and enable consistent implementation of administrative measures (such as triage, respiratory isolation, prompt treatment, and disinfection of surfaces and equipment). This also means that HWs are entitled to, and should have access to, high-quality PPE sufficient to protect against both droplet and aerosol transmission, with efforts made to minimise exposure.

We therefore make the following recommendations:

1. Particulate FFP respirators should be worn by:

a. all staff (clinical and non-clinical) during activities that involve contact or sharing air in indoor spaces (more so if poorly ventilated) with individuals who $(i)$ have not yet been clinically evaluated or (ii) are thought or known to have TB and/or COVID-19 (this will likely include waiting areas, emergency departments, clinic consultation rooms, and certain inpatient wards and high care/intensive care units);

b. frontline staff in clinical areas who are in contact with patients thought or known to have TB, COVID-19, or other respiratory infection, including influenza, measles, and varicella (likely areas include emergency departments, medical admissions units, and 'patients under investigation' (PUI) wards); and

c. any staff involved in high-risk or aerosolising procedures involving individuals thought or known to have TB or COVID-19 (e.g. bronchoscopy, open or closed suctioning of the airway, non-invasive ventilation, oxygen, and dental procedures, among others).

2. Respirators (N95, FFP2, and other equivalent respirators, e.g. quality-assured KN95 masks) should fulfil the following requirements, per criteria set out by SA National Department of Health $(\mathrm{NDoH})^{[99]}$ and the USA National Institute for Occupational Safety and Health (NIOSH; see Box 1). ${ }^{[100]}$

a. All respirators should be accompanied by Homologation Certificates, proof of international compliance, and quality certificates. The filter designation, manufacturer, model number, and certification approval number should be displayed on the body of the respirator.

b. All respirators require a clear physical marking with $(i)$ the manufacturer/brand name/registered trademark; (ii) an alphanumeric rating as recognised (e.g. FFP2, FFP3, N95, KN95); (iii) a standard compliance label showing the standard/s the device has met; (iv) the size of the respirator, model number, and lot number; and $(v)$ any other mandatory markings.

The respirator should, at minimum, be evaluated by qualitative fit testing. ${ }^{[101]}$ Fit testing forms an indispensable part of achieving the objective filtration of virus and bacteria and should be carried out at least annually for every HW required to wear a respirator, in accordance with the respirator's brand and size. Additional fit testing is generally recommended if the subject experiences a weight change of $\geq 10 \mathrm{~kg}$ or has significant dental changes, reconstructive surgery, or facial disfigurement. ${ }^{[99]}$ We recommend that healthcare facilities have access to low-cost qualitative fit testing equipment 


\section{Certification}

All particulate filtering facepiece respirators sold should be accompanied by Homologation Certificates, proof of international compliance (in the case of imported RPE including NIOSH approvals, European Union certifications, CE marking reports, and complete FDA registrations) and quality certificates. The minimum required stipulation is:

1. Total inward leakage using quantitative and/or qualitative fit tests (performed at facility level on individuals);

2. Determination of particulate filter penetration (PFP) with the minimum testing requirement being to $\mathrm{NaCl}$ filtration (and only where possible to paraffin oil and latex particles);

3. Determination of flow resistance (inhalation resistance at a minimum, but preferably inhalation and exhalation resistance with the latter mandatory for valved respirators);

4. Flammability testing;

5. Fluid resistance test (this test is not mandatory at this time owing to capacity and development constraints in lab testing in SA). Where fluid resistance testing has not been conducted by a verified international lab but all other local tests pass, the recommendation is for mandatory visor usage to protect against respirator fluid exposure.

\section{Metrology notification}

All filtering facepiece respirators (SAHPRA Class B device) in the interests of identification, safety and to ensure that homologation is possible and accurate should have a clear physical marking/stamp on each mask or respirator with the mandatory (in bold) minimum information being:

1. Manufacturer/brand name/registered trademark or easily understood abbreviation,

2. The mask or respirator efficiency classification; an alphanumeric rating as recognised (e.g., FFP2, FFP3, N95, KN95);

3. Standard compliance label that indicates the local SANS standard showing the device has been tested against and passed;

4. Size of the respirator, model number and lot number; and

5. Any other mandatory markings as required by SANAS, NRCS, SAHPRA, other national regulator or standard and as may be required by the Legal Metrology Act, 2014 (Act 9 of 2014).

Box 1. Quality requirements for particulate filtering facepiece respirators in South Africa. (FDA = United States Food and Drug Administration; NRCS = National Regulator for Compulsory Specifications; RPE = respiratory protective equipment; SAHPRA = South African Health Products Regulatory Authority; SANAS = South African National Accreditation System; SANS = South African National Standard.) (Adapted from the SA National Department of Health's Policy for the Regulation of Quality Respiratory Protective Equipment (RPE) Supply in Healthcare (2020). ${ }^{[99]}$ )

(e.g. the $3 \mathrm{M}$ Qualitative Fit Test Apparatus FT-10 (3M, SA) $)^{[50]}$ so that respirators and wearers can be evaluated. Qualitative fit testing is simpler and cheaper than quantitative testing. This may be at individual healthcare facilities or through local or regional centres. This will also provide regulatory bodies an opportunity to evaluate masks that claim to meet N95 or FFP2 standards and will go towards establishing a 'respiratory protection programme' for HWs, in line with international guidance. ${ }^{[20]}$ To meet new recommendations by the South African Health Products Regulatory Authority (SAHPRA), ${ }^{[102]}$ regional or national comprehensive testing nodes should be established to perform more rigorous quantitative fit testing (for example, using the ambient aerosol condensation nuclei counter protocol ${ }^{[101]}$ and evaluation of filtration integrity. There is currently negligible access to such facilities in the SA public or private sectors.

3. It is critical to emphasise that particulate respirators alone are less likely to be effective if other IPC measures are not implemented. Therefore, in line with international IPC guidelines, ${ }^{[19,20]}$ a 'package of care' approach should be adopted, the major elements of which are detailed in Table 2.

We also note that the practice of wearing a surgical mask over a fit tested quality respirator to prevent contamination or improve efficacy is not evidence based, has not been evaluated scientifically, and may unnecessarily increase the work of breathing. Wearing a surgical mask underneath a respirator is not recommended as it is likely to compromise fit and therefore the efficacy of the respirator. In addition, given the occurrence of breakthrough infections with SARS-CoV-2 in individuals who have received a partial or even full vaccination course, ${ }^{[103]}$ no differentiation should be made according to vaccination status as regards to use of PPE.

\section{Hurdles and challenges}

Our aim is to make recommendations for measures that will provide the highest level of protection to HWs and patients, regardless of the logistical obstacles. We recognise, however, that these recommendations may not be straightforward to implement. Health systems have been severely affected by the global shortage of quality respirators and are facing challenges with procurement and manufacturing. The $\mathrm{NDoH}$ should work with manufacturers, regulatory bodies, and other relevant parties to find ways to overcome challenges to better serve HWs. We also urge manufacturers to explore improving the comfort of respirators and to take measures to reduce barriers to communication (e.g. by using transparent materials to allow lipreading). Innovative methods should be explored to produce new masks (e.g. 3D printing) without compromising on quality. ${ }^{[104,105]}$

The US CDC states that respirators are 'meant to be disposed after each use, but also describes contingency strategies in the case of acute shortages or crisis, including 'decontamination' (e.g. with UVGI, hydrogen peroxide, or moist heat, also known as 'reprocessing'), 'extended use' (continuous use of the same respirator for encounters with multiple patients), and 'limited reuse' (use of the same respirator for encounters with multiple patients, with the respirator donned and 
Table 2. Major elements of a 'package of control' approach to infection prevention and control for airborne infections in healthcare facilities

\begin{tabular}{|c|c|}
\hline Category & Details or examples \\
\hline Administrative & $\begin{array}{l}\text { Examples include triage and separation of people with infectious or potentially } \\
\text { infectious TB, COVID-19, and/or influenza, etc. }\end{array}$ \\
\hline Environmental & $\begin{array}{l}\text { E.g. ensuring good ventilation (minimum } 6 \text { - } 12 \text { air changes per hour equivalent), } \\
\text { minimising crowding, and using UVGI }\end{array}$ \\
\hline Personal protection & $\begin{array}{l}\text { Using high-quality PPE as appropriate (e.g. respirators, eye protection, gloves, } \\
\text { aprons) }\end{array}$ \\
\hline $\begin{array}{l}\text { Additional measures to reduce transmission } \\
\text { between clinic attendees and from clinic } \\
\text { attendees to HWs }\end{array}$ & $\begin{array}{l}\text { E.g. face coverings for all individuals attending health facilities (source control), } \\
\text { physical distancing, and hand hygiene }\end{array}$ \\
\hline $\begin{array}{l}\text { Additional measures to reduce transmission } \\
\text { between HWs }\end{array}$ & $\begin{array}{l}\text { Attention to IPC in non-clinical areas such as staff canteens, rest areas, and changin } \\
\text { rooms }\end{array}$ \\
\hline $\begin{array}{l}\text { Additional measures to reduce transmission to } \\
\text { and from HWs outside of healthcare facilities }\end{array}$ & $\begin{array}{l}\text { HWs trained to maintain precautions outside of health facilities. For example, } \\
\text { during use of public transport; by minimising time spent in poorly ventilated, } \\
\text { densely occupied areas; and by maintaining physical distancing, hand hygiene, and } \\
\text { use of face coverings }\end{array}$ \\
\hline $\begin{array}{l}\text { Longer-term measures to strengthen systems and } \\
\text { reduce risks of transmission }\end{array}$ & $\begin{array}{l}\text { Respiratory protection programmes; surveillance for healthcare-associated } \\
\text { infections; monitoring/audit of IPC practices with feedback }{ }^{*}\end{array}$ \\
\hline
\end{tabular}

$\mathrm{TB}=$ tuberculosis; COVID-19 = coronavirus disease 2019; UVGI = ultraviolet germicidal irradiation; $\mathrm{HW}=$ health worker; $\mathrm{PPE}=$ personal protective equipment; $\mathrm{IPC}=$ infection prevention and control ${ }^{*}$ See 'core components of IPC programmes' in 2019 WHO TB IPC guidelines. ${ }^{[20]}$

doffed between encounters). ${ }^{[106]}$ Each approach carries risks, most importantly of reductions in respirator fit and filtration performance, but also of contamination and self-contamination through repeated donning and doffing. ${ }^{[107-109]}$ As such, SAHPRA and NDoH currently prohibit decontamination/reprocessing of respirators by any method but, in the case of shortages or if supply optimisation is required, do support extended use (with no attempts at cleaning or decontaminating and ideally without repeated donning and doffing) of single-use respirators for up to 6 - 8 hours, depending on the manufacturer. ${ }^{[99]}$

From a long-term IPC perspective, a focus on respirator use risks over-emphasising individual protection, shifting responsibility back to individual HWs and lessening pressure on the healthcare system to make the structural changes needed to improve the health and safety of the working environment. We recognise that persistent advocacy and research to support broader systems change are needed. ${ }^{[110,111]}$ As previously suggested, ${ }^{[8]}$ improved routine reporting of the incidence of TB, COVID-19, and other occupationally-acquired illnesses among HWs will help monitor the longer-term effects of preventive measures and help drive advocacy.

\section{Conclusion}

SARS-CoV-2 and $M t b$ are transmitted via aerosol. HWs are at high risk of infection. The use of surgical masks in frontline settings is inappropriate. Fit-tested particulate FFP respirators provide better protection against infectious aerosols than surgical masks, are already recommended for use by all HWs in high TB burden countries and many COVID-19 pandemic settings, and should be worn routinely to protect HWs against TB and COVID- 19.

\section{Acknowledgements. None.}

Author contributions. Equal contributions.

Funding. KD acknowledges funding from the SA MRC (RFA-EMU-02-2017),
EDCTP (TMA-2015SF-1043, TMA-1051-TESAII, TMA-CDF2015), UK Medical Research Council (MR/S03563X/1) and the Wellcome Trust (MR/ S027777/1). HJZ is funded by the SA-MRC and the UK MRC (GEC1111). FV's unit acknowledges funding from the Bill \& Melinda Gates Foundation (BMGF), South African Medical Research Council, National Institutes for Health, AIDS Fonds, Unitaid, Foundation for Innovative New Diagnostics and the Children's Investment Fund Foundation, amongst others. GJC is funded by NIH/DAIDS, Unitaid, BMGF, CEPI, and ViiV. NN gratefully acknowledges funding from the NRF, SA-MRC, UK MRC, and the Lily and Ernst Haussmann Trust.

Conflicts of interest. Dr Martinson's institution receives grants from Pfizer for research into pneumonia. All other authors have no conflict of interest to declare.

1. National Institute for Communicable Diseases, South Africa. COVID-19 Weekly Epidemiological Brief: Week 36 (2021). Pretoria: NICD, 2021. https://www.nicd. ac.za/wp-content/uploads/2021/09/COVID-19-Weekly-Epidemiology-Briefweek-36-2021.pdf (accessed 17 September 2021)

2. Greenhalgh T, Jimenez JL, Prather KA, Tufekci Z, Fisman D, Schooley R. Ten scientific reasons in support of airborne transmission of SARS-CoV-2. Lancet 2021;397(10285):1603-1605. https://doi.org/10.1016/s0140-6736(21)00869-2

3. Network for Genomic Surveillance South Africa. SARS-CoV-2 Sequencing Update (19 July 2021). Pretoria: NICD, 2021. https://www.nicd.ac.za/wp-content/ uploads/2021/07/Update-of-SA-sequencing-data-from-GISAID-19-July-2021.pdf (accessed 27 July 2021)

4. Subramanian R, He Q, Pascual M. Quantifying asymptomatic infection and transmission of COVID-19 in New York City using observed cases, serology, and testing capacity. Proc Natl Acad Sci 2021;118(9)e2019716118. https://doi.org/10.1073/ pnas. 2019716118

5. Yanes-Lane M, Winters N, Fregonese F, et al. Proportion of asymptomatic infection among COVID-19 positive persons and their transmission potential: A systematic review and meta-analysis. PLoS ONE 2020;15(11)e0242536. https://doi.org/10.1371/ journal.pone.0241536

6. Qiu X, Nergiz AI, Maraolo AE, Bogoch II, Low N, Cevik M. The role of asymptomatic and pre-symptomatic infection in SARS-CoV-2 transmission - a living systematic review. Clin Microbiol Infect Off Publ Eur Soc Clin Microbiol Infect Dis 2021;27(4):511-519. https://doi.org/10.1016/j.cmi.2021.01.011

7. Bandyopadhyay S, Baticulon RE, Kadhum M, et al. Infection and mortality of healthcare workers worldwide from COVID-19: A systematic review. BMJ Glob Health 2020;5(12):e003097. https://doi.org/10.1136/bmjgh-2020-003097 
8. Grobler L, Mehtar S, Dheda K, et al. The epidemiology of tuberculosis in health care workers in South Africa: a systematic review. BMC Health Serv Res 2016;16(1):416. https://doi.org/10.1186/s12913-016-1601-5

9. Uden L, Barber E, Ford N, Cooke GS. Risk of tuberculosis infection and disease for healthcare workers: An updated meta-analysis. Open Forum Infect Dis 2017;4(3):Ofx137. https://doi.org/10.1093/ofid/ofx137

10. Adams S, Ehrlich R, Baatjies R, et al. Incidence of occupational latent tuberculosis infection in South African healthcare workers. Eur Respir J 2015;45(5):1364-1373. https://doi.org/10.1183/09031936.00138414

11. Jarand J, Shean K, O'Donnell M, et al. Extensively drug-resistant tuberculosis (XDRTB) among healthcare workers in South Africa. Trop Med Int Health 2010;15(10):11791184. https://doi.org/10.1111/j.1365-3156.2010.02590.x

12. World Health Organization. Tuberculosis profile: South Africa (2019). Geneva: WHO, 2019. https://worldhealthorg.shinyapps.io/tb_profiles/?_inputs_\&entity_ type $=\% 22$ country $\% 22 \& l a n=\% 22$ EN\%22\&iso2 $=\% 22 Z$ A $\% 22$ (accessed 6 June 2021)

13. Brunet L, Pai M, Davids V, et al. High prevalence of smoking among patients with suspected tuberculosis in South Africa. Eur Respir J 2011;38(1):139-146. https://doi. org/10.1183/09031936.00137710

14. van Zyl Smit RN, Pai M, Yew WW, et al. Global lung health: The colliding epidemics of tuberculosis, tobacco smoking, HIV and COPD. Eur Respir J 2010;35(1):27-33. https://doi.org/10.1183/09031936.00072909

15. Lin H-H, Ezzati M, Murray M. Tobacco smoke, indoor air pollution and tuberculosis: A systematic review and meta-analysis. PLoS Med 2007;4(1):e20. https://doi. org/10.1371/journal.pmed.0040020

16. Ehrlich R, Akugizibwe P, Siegfried N, Rees D. The association between silica exposure, silicosis and tuberculosis: A systematic review and meta-analysis. BMC Public Health 2021;21(1):953. https://doi.org/10.1186/s12889-021-10711-1

17. Boulle A, Davies M-A, Hussey H, et al. Risk factors for COVID-19 death in a population cohort study from the Western Cape Province, South Africa. Clin Infect Dis Off Publ Infect Dis Soc Am 2020;73(7):e2005-e2015. https://doi.org/10.1093/cid/ciaal198

18. World Health Organization. Infection prevention and control during health care when coronavirus disease (COVID-19) is suspected or confirmed (interim guidance 12 July 2021). Geneva: WHO, 2021. https://apps.who.int/iris/rest/bitstreams/1356030/ retrieve (accessed 27 July 2021)

19. World Health Organization. COVID-19: Occupational health and safety for health workers. Interim guidance - 2 February 2021. Geneva: WHO, 2021. https://apps. who. int/iris/rest/bitstreams/1329986/retrieve (accessed 2 May 2021)

20. World Health Organization. WHO guidelines on tuberculosis infection prevention and control: 2019 update. Geneva: WHO, 2019. https://apps.who.int/iris/bitstream/ handle/10665/311259/9789241550512-eng.pdf?ua=1 (accessed 1 December 2019)

21. South Africa National Department of Health. COVID-19 Disease: Infection Prevention and Control Guidelines. Version 2 (21st May 2020). Pretoria: NDoH, 2020. https://www.nicd.ac.za/wp-content/uploads/2020/05/ipc-guidelines-covid-19version-2-21-may-2020.pdf

22. Brown J, Gregson FKA, Shrimpton A, et al. A quantitative evaluation of aerosol generation during tracheal intubation and extubation. Anaesthesia 2020;76:151-155. https://doi.org/10.1111/anae.15292

23. Shrimpton A, Gregson FKA, Cook TM, et al. A quantitative evaluation of aerosol generation during tracheal intubation and extubation: A reply. Anaesthesia 2021;76(S3):16-18. https://doi.org/10.1111/anae.15345

24. Chanpong B, Tang M, Rosenczweig A, Lok P, Tang R. Aerosol-generating procedures, and simulated cough in dental anaesthesia. Anaesth Prog 2020;67(3):127-134. https:// doi.org/10.2344/anpr-67-03-04

25. Fennelly KP. Particle sizes of infectious aerosols: Implications for infection control. Lancet Respir Med 2020;8(9):914-924. https://doi.org/10.1016/

26. van Doremalen N, Bushmaker T, Morris DH, et al. Aerosol and surface stability of SARS-CoV-2 as compared with SARS-CoV-1. N Engl J Med 2020;382(16):1564-1567. https://doi.org/10.1056/nejmc2004973

27. Lednicky JA, Lauzardo M, Fan ZH, et al. Viable SARS-CoV-2 in the air of a hospital room with COVID-19 patients. Int J Infect Dis IJID Off Publ Int Soc Infect Dis 2020;100:476-482. https://doi.org/10.1016/j.ijid.2020.09.025

28. Lednicky JA, Lauzardo M, Alam MM, et al. Isolation of SARS-CoV-2 from the air in a car driven by a COVID patient with mild illness. Int J Infect Dis IJID Off Publ Int Soc Infect Dis 2021;108:212-216. https://doi.org/10.1016/j.ijid.2021.04.063

29. Kutter JS, de Meulder D, Bestebroer TM, et al. SARS-CoV and SARS-CoV-2 are transmitted through the air between ferrets over more than one meter distance. Nat Commun 2021;12(1):1653. https://doi.org/10.1038/s41467-021-21918-6

30. Nissen K, Krambrich J, Akaberi D, et al. Long-distance airborne dispersal of SARSCoV-2 in COVID-19 wards. Sci Rep 2020;10(1):19589. https://doi.org/10.1038/ s41598-020-76442-2

31. Schijven J, Vermeulen LC, Swart A, Meijer A, Duizer E, de Roda Husman AM. Quantitative microbial risk assessment for airborne transmission of SARS-CoV-2 via breathing, speaking, singing, coughing, and sneezing. Environ Health Perspect 2021;129(4):47002. https://doi.org/10.1289/ehp7886
32. Crawford C, Vanoli E, Decorde B, et al. Modeling of aerosol transmission of airborne pathogens in ICU rooms of COVID-19 patients with acute respiratory failure. Sci Rep 2021;11:11778. https://doi.org/10.1038/s41598-021-91265-5

33. Basu S, Stuckler D, McKee M. Addressing institutional amplifiers in the dynamics and control of tuberculosis epidemics. Am J Trop Med Hyg 2011;84(1):30-37. https://doi. org/10.4269\%2Fajtmh.2011.10-0472

34. Read JM, Green CA, Harrison EM, et al. Hospital-acquired SARS-CoV-2 infection in the UK's first COVID-19 pandemic wave. Lancet Lond Engl 2021;398(110305):10371038. https://doi.org/10.1016/s0140-6736(21)01786-4

35. Lessells R, Moosa Y, de Oliveira T. Report into a nosocomial outbreak of coronavirus disease 2019 (COVID-19) at Netcare St. Augustine's Hospital. 2020. https:// www.krisp.org.za/manuscripts/StAugustinesHospitalOutbreakInvestigation FinalReport_15may2020_comp.pdf (accessed 26 January 2021)

36. Menzies D, Fanning A, Yuan L, Fitzgerald M. Tuberculosis among healthcare workers. N Engl J Med 1995;332(2):92-98. https://doi.org.10.1056/NEJM199501123320206

37. Menzies D, Joshi R, Pai M. Risk of tuberculosis infection and disease associated with work in healthcare settings. Int J Tuberc Lung Dis 2007;11(6):593-605.

38. Joshi R, Reingold AL, Menzies D, Pai M. Tuberculosis among healthcare workers in low- and middle-income countries: A systematic review. PLoS Med 2006;3(12):23762391. https://doi.org/10.1371/journal.pmed.0030494

39. Baussano I, Nunn P, Williams B, Pivetta E, Bugiani M, Scano F. Tuberculosis among healthcare workers. Emerg Infect Dis 2011;17(3):488-494. https://doi. org/10.3201\%2Feid1703.100947

40. Ambrosioni J, Blanco JL, Reyes-Urueña JM, et al. Overview of SARS-CoV-2 infection in adults living with HIV. Lancet HIV 2021;8(5):e294-305. https://doi.org/10.1016/ s2352-3018(21)00070-9

41. World Health Organization, International Labour Office. Joint WHO/ILO policy guidelines on improving health worker access to prevention, treatment and care services for HIV and TB. Geneva: WHO, 2010. https://apps.who.int/iris/ handle/10665/44467 (accessed 5 Oct 2021)

42. South Africa Ministry of Health. Statement on healthcare workers that have acquired COVID-19. Pretoria, Ministry of Health, 2020. https://storage.googleapis. com/stateless-bhekisisa-website/wordpress-uploads/2020/08/fda38e56-hcw-13august-2020.pdf (accessed 4 May 2021)

43. Jordan B. COVID-19 killed 339 state healthcare workers between March and November. TimesLIVE. 2021. https://www.timeslive.co.za/news/south-africa/2021 01-06-covid-19-killed-339-state-health-care-workers-between-march-andnovember/ (accessed 4 May 2021)

44. Kambhampati AK. COVID-19-associated hospitalisations among healthcare personnel - COVID-NET, 13 States, March 1 - May 31, 2020. MMWR Morb Mortal Wkly Rep 2020;69.

45. Spencer J, Jewett C. Twelve months of trauma: More than 3600 US health workers died in COVID's first year. The Guardian. 2021. https://www.theguardian.com/usnews/2021/apr/08/us-health-workers-deaths-covid-lost-on-the-frontline (accessed 4 May 2021)

46. South Africa. Occupational Health and Safety Act No. 85 of 1993.

47. De Raeve P, Adams E, Xyrichis A. The impact of the COVID-19 pandemic on nurses in Europe: A critical discussion of policy failures and opportunities for future preparedness. Int J Nurs Stud Adv 2021;3:100032. https://doi.org/10.1016/j. ijnsa.2021.100032

48. Saba A, Jika T. Eastern Cape's PPE shortage endangers healthcare workers. The Mail \& Guardian. 23 April 2020. https://mg.co.za/article/2020-04-23-eastern-capes-ppe-shortageendangers-healthcare-workers/

49. World Health Organization. Shortage of personal protective equipment endangering health workers worldwide. Geneva: WHO, 2020. https://www.who.int/news/item/0303-2020-shortage-of-personal-protective-equipment-endangering-health-workersworldwide (accessed 8 June 2021)

50. Mottay L, Le Roux J, Perumal R, et al. KN95 filtering facepiece respirators distributed in South Africa fail safety testing protocols. S Afr Med J 2020;111(3):234. https://doi. org/10.7196/samj.2021.v111i3.15381

51. Griffith DE, Cegielski JP. Tuberculosis healthcare workers: There goes my hero. Clin Infect Dis Off Publ Infect Dis Soc Am 2020;72(1):27-29. https://doi.org/10.1093/cid/ciaa716

52. Ehrlich R, Spiegel JM, Adu P, Yassi A. Current guidelines for protecting health workers from occupational tuberculosis are necessary, but not sufficient: Towards a comprehensive occupational health approach. Int J Environ Res Public Health 2020;17(11):3957. https://doi.org/10.3390/ijerph17113957

53. Bourgeault IL, Maier CB, Dieleman M, et al. The COVID-19 pandemic presents an opportunity to develop more sustainable health workforces. Hum Resour Health 2020;18(83). https://doi.org/10.1186/s12960-020-00529-0

54. Dheda K, Makambwa E, Esmail A. The great masquerader: Tuberculosis presenting as community-acquired pneumonia. Semin Respir Crit Care Med 2020;41(4):592-604. https://doi.org/10.1055/s-0040-1710583 
55. Aston SJ, Rylance J. Community-acquired pneumonia in sub-Saharan Africa. Semin Respir Crit Care Med 2016;37(6):855-867. https://doi.org/10.1055/s-0036-1592126

56. Frascella B, Richards AS, Sossen B, et al. Subclinical tuberculosis disease - a review and analysis of prevalence surveys to inform definitions, burden, associations, and screening methodology. Clin Infect Dis 2020;73(3):e830-e841 https://doi.org/10.1093/ $\mathrm{cid} / \mathrm{ciaa} 1402$

57. Mvusi L. First national TB prevalence survey, South Africa, 2017-19. Abstract, 51st Union World Conference on Lung Health. 20 - 24 October 2020.

58. Govender I, Karat AS, Baisley K, et al. Prevalence of Mycobacterium tuberculosis in sputum among adult clinic attendees compared with the surrounding community in rural South Africa: Implications for finding the missing millions. Abstract, 51st World Conf Lung Health Int Union Tuberc Lung Dis. 20 - 24 October 2020.

59. Walaza S, Tempia S, Dreyer A, et al. The burden and clinical presentation of pulmonary tuberculosis in adults with severe respiratory illness in a high human immunodeficiency virus prevalence setting, 2012-2014. Open Forum Infect Dis 2017;4(3):Ofx116. https://doi.org/10.1093\%2Fofid\%2Fofx116

60. Chihota VN, Ginindza S, McCarthy KM, Grant AD, Churchyard GJ, Fielding KL. Missed opportunities for TB investigation in primary care clinics in South Africa: Experience from the XTEND trial. PLoS ONE 2015;10(9). https://doi.org/10.1371/ journal.pone.0138149

61. Kweza PF, Van Schalkwyk C, Abraham N, Uys M, Claassens MM, Medina-Marino A. Estimating the magnitude of pulmonary tuberculosis patients missed by primary healthcare clinics in South Africa. Int J Tuberc Lung Dis Off J Int Union Tuberc Lung Dis 2018;22(3):264-272. https://doi.org/10.5588/ijtld.17.0491

62. Yates TA, Khan PY, Knight GM, et al. The transmission of Mycobacterium tuberculosis in high burden settings. Lancet Infect Dis 2016;16(2):227-238. https://doi.org/10.1016/ s1473-3099(15)00499-5

63. Amalberti R, Vincent C. Managing risk in hazardous conditions: Improvisation is no enough. BMJ Qual Saf 2020;29(1):60-63. https://doi.org/10.1136/bmjqs-2019-009443

64. Wizner K, Nasarwanji M, Fisher E, Steege AL, Boiano JM. Exploring respiratory protection practices for prominent hazards in healthcare settings. J Occup Environ Hyg 2018;15(8):588-597. https://doi.org/10.1080/15459624.2018.1473581

65. Wells W. On air-borne infection: Study II. Droplets and droplet nuclei. Am J Epidemiol 1934;20(3):611-618. https://doi.org/10.1093/oxfordjournals.aje.al18097

66. Loudon RG, Roberts RM. Droplet expulsion from the respiratory tract. Am Rev Respir Dis 1967;95(3):435-442. https://doi.org/10.1164/arrd.1967.95.3.435

67. Leung NHL. Transmissibility and transmission of respiratory viruses. Nat Rev Microbiol 2021;19:528-545. https://doi.org/10.1038/s41579-021-00535-6

68. Asadi S, Wexler AS, Cappa CD, Barreda S, Bouvier NM, Ristenpart WD. Aerosol emission and superemission during human speech increase with voice loudness. Sci Rep 2019;9(1):2348. https://doi.org/10.1038/s41598-019-38808-Z

69. Stadnytskyi V, Anfinrud P, Bax A. Breathing, speaking, coughing or sneezing: What drives transmission of SARS-CoV-2? J Intern Med 2021;(8). https://doi.org/10.1111/ joim. 13326

70. Churchyard G, Kim P, Shah NS, et al. What we know about tuberculosis transmission An overview. J Infect Dis 2017;216(6):S629-635. https://doi.org/10.1093/infdis/jix362

71. World Health Organization. Infection prevention and control during health care when coronavirus disease (COVID-19)" is suspected or confirmed. (Interim guidance, 29 June 2020). Geneva: WHO, 2020. https://apps.who.int/iris/rest/bitstreams/1284718/ retrieve (accessed 3 May 2021)

72. South Africa National Department of Health. COVID-19: Infection prevention and control guidelines. Version 1 (April 2020). Pretoria: NDoH, 2020. https://www.nicd. ac.za/wp-content/uploads/2020/04/Covid019-infection-and-Prevention-ControlGuidelines-1-April-2020.pdf

73. MacIntyre CR, Ananda-Rajah MR. Scientific evidence supports aerosol transmission of SARS-COV-2. Antimicrob Resist Infect Control 2020;9(202). https://doi. org/10.1186/s13756-020-00868-6

74. Tang JW, Bahnfleth WP, Bluyssen PM, et al. Dismantling myths on the airborne transmission of severe acute respiratory syndrome coronavirus-2 (SARS-CoV-2). J Hosp Infect 2021;110:89-96. https://doi.org/10.1016\%2Fj.jhin.2020.12.022

75. Dancer SJ, Tang JW, Marr LC, Miller S, Morawska L, Jimenez JL. Putting a balance on the aerosolisation debate around SARS-CoV-2. J Hosp Infect 2020;105(3):569-570. https://doi.org/10.1016\%2Fj.jhin.2020.05.014

76. World Health Organization. Roadmap to improve and ensure good indoor ventilation in the context of COVID-19. 1 March 2021. Geneva: WHO, 2021. https://apps.who. int/iris/rest/bitstreams/1333991/retrieve (accessed 2 May 2021).

77. Centers for Disease Control and Prevention. COVID-19: Ventilation in Buildings [Updated 2 June 2021]. Atlanta: CDC, 2021. https://www.cdc.gov/coronavirus/2019ncov/community/ventilation.html (accessed 8 June 2021)

78. Stockwell RE, Ballard EL, O’Rourke P, Knibbs LD, Morawska L, Bell SC. Indoor hospital air and the impact of ventilation on bioaerosols: A systematic review. J Hosp Infect 2019;103(2):175-184. https://doi.org/10.1016/j.jhin.2019.06.016
79. Chan P-C, Fang C-T. The role of ventilation in tuberculosis control. J Formos Med Assoc 2021;120(6):1293-1295. https://doi.org/10.1016/j.jfma.2020.11.003

80. Ramaraj P, Super J, Doyle R, Aylwin C, Hettiaratchy S. Triaging of respiratory protective equipment on the assumed risk of SARS-CoV-2 aerosol exposure in patient-facing healthcare workers delivering secondary care: A rapid review. BM] Open 2020;10(10).e040321 https://doi.org/10.1136/bmjopen-2020-040321

81. Iannone P, Castellini G, Coclite D, et al. The need of health policy perspective to protect healthcare workers during COVID-19 pandemic. A GRADE rapid review on the N95 respirators effectiveness. PLoS ONE 2020;15(6):e0234025. https://doi. org/10.1371\%2Fjournal.pone.0234025

82. MacIntyre CR, Chughtai AA. A rapid systematic review of the efficacy of face masks and respirators against coronaviruses and other respiratory transmissible viruses for the community, healthcare workers and sick patients. Int J Nurs Stud 2020;108:103629. https://doi.org/10.1016\%2Fj.ijnurstu.2020.103629

83. MacIntyre CR, Wang Q, Seale H, et al. A randomised clinical trial of three options for N95 respirators and medical masks in health workers. Am J Respir Crit Care Med 2013;187(9):960-966. https://doi.org/10.1164/rccm.201207-1164oc

84. Chu DK, Akl EA, Duda S, et al. Physical distancing, face masks, and eye protection to prevent person-to-person transmission of SARS-CoV-2 and COVID-19: A systematic review and meta-analysis. Lancet Lond Engl 2020;395(10242):1973-1987. https://doi. org/10.1016/S0140-6736(20)31142-9

85. Public Health England. COVID-19: infection prevention and control (IPC) (version 1.2, updated 1 June 2021). London: PHE, 2021. https://assets.publishing.service.gov. uk/government/uploads/system/uploads/attachment_data/file/990923/20210602_ Infection_Prevention_and_Control_Guidance_for_maintaining_services_with_H_ and_C_settings_1_.pdf (accessed 8 June 2021)

86. South Africa. Occupational Health and Safety Act No 85 of 1993. Regulations: Hazardous biological agents. 2001. https://www.gov.za/documents/occupationalhealth-and-safety-act-regulations-hazardous-biological-agents (accessed 17 September 2021)

87. South Africa National Department of Health. Practical manual for implementation of the national infection prevention and control strategic framework. Pretoria: NDoH, 2020. https://www.nicd.ac.za/wp-content/uploads/2020/04/Practical-Manual-forimplementation-of-the-National-IPC-Strategic-Framework-March-2020-1.pdf (accessed 2 May 2021)

88. South Africa Department of Employment and Labour. Workplace preparedness COVID-19 (SARS-CoV-19 virus). Pretoria: DoE\&L, 2020. http://www.labour.gov. za/DocumentCenter/Publications/Occupational\%20Health\%20and\%20Safety/ COVID-19\%20Guideline\%20Mar2020.pdf (accessed 17 September 2021)

89. South Africa Department of Employment and Labour. Consolidated direction on occupational health and safety measures in certain workplaces. Pretoria: DoE\&L, 2021. https://www.nioh.ac.za/wp-content/uploads/2021/06/Consolidated-Directionon-Occupational-Health-and-Safety-measures-in-certain-workplaces_May2021.pdf (accessed 5 October 2021)

90. Centers for Disease Control and Prevention. Guidelines for preventing the transmission of Mycobacterium tuberculosis in healthcare settings, 2005. Atlanta: CDC, 2005. https://www.cdc.gov/mmwr/preview/mmwrhtml/rr5417a1.htm?s_ cid=rr5417a1_e (accessed 8 June 2021)

91. Centers for Disease Control and Prevention. Interim infection prevention and control recommendations for healthcare personnel during the coronavirus disease 2019 (COVID-19) pandemic (updated Feb. 23, 2021). Atlanta: CDC, 2021. https:// www.cdc.gov/coronavirus/2019-ncov/hcp/infection-control-recommendations.html (accessed 8 June 2021)

92. Diel R, Nienhaus A, Witte P, Ziegler R. Protection of healthcare workers against transmission of Mycobacterium tuberculosis in hospitals: A review of the evidence. ERJ Open Res 2020;6(1):00317-2019. https://doi.org/10.1183\%2F23120541.00317-2019

93. European Centre for Disease Prevention and Control. European Union standards for tuberculosis care - 2017 update. Brussels: ECDC, 2017. https://www.ecdc.europa.eu/ sites/default/files/documents/ESTC-leaflet-September-2018.pdf (accessed 8 June 2021)

94. European Centre for Disease Prevention and Control. Infection prevention and control and preparedness for COVID-19 in healthcare settings (Sixth update - 9 February 2021). Brussels: ECDC, 2021. https://www.ecdc.europa.eu/sites/default/ files/documents/Infection-prevention-and-control-in-healthcare-settings-COVID19_6th_update_9_Feb_2021.pdf (accessed 8 June 2021)

95. National Centre for Disease Control, Directorate General of Health Services, Ministry of Health and Family Welfare, Government of India. National Guidelines for infection prevention and control in healthcare facilities. New Delhi: NCDC, 2020. https://main. mohfw.gov.in/sites/default/files/National\%20Guidelines\%20for\%20IPC\%20in\%20 HCF\%20-\%20final\%281\%29.pdf (accessed 8 June 2021).

96. Government of India: Ministry of Health and Family Welfare. Clinical management protocol for COVID-19 (inadults) -version6,24May2021.NewDelhi:MoHFW,2021.https://www.mohfw. gov.in/pdf/COVID19ClinicalManagementProtocolAlgorithmAdults19thMay2021.pdf (accessed 8 June 2021). 
97. Richter ED, Laster R. The precautionary principle, epidemiology, and the ethics of delay. Int J Occup Med Environ Health 2004;17(1):9-16.

98. Davis DJ. Going beyond benchmarks: Zero harm for every patient, every time. J Nurs Adm 2015;45(4):183-184. https://doi.org/10.1097/nna.0000000000000180

99. South Africa National Department of Health. Policy for the regulation of quality respiratory protective equipment (RPE) supply in healthcare (August 2020). Pretoria: NDoH, 2020. https://www.nicd.ac.za/wp-content/uploads/2020/11/RPE-Policy-20August-2020-Signed.pdf (accessed 27 July 2021)

100. The National Institute for Occupational Safety and Health. Approved particulate filtering facepiece respirators. Atlanta: NIOSH, 2020. https://www.cdc.gov/niosh/npptl/ topics/respirators/disp_part/default.html

101. Occupational Safety and Health Administration. Fit testing procedures (Mandatory). Washington DC: OSHA, 2004. https://www.osha.gov/laws-regs/regulations/ standardnumber/1910/1910.134AppA (accessed 6 June 2021)

102. South African Health Products Regulatory Authority. Communication to stakeholders. MD025: Licensing and regulatory requirements for the manufacture and distribution of medical and respirator masks during COVID-19. Pretoria: SAHPRA, 2020. https:// www.sahpra.org.za/wp-content/uploads/2020/09/MD025_Alternative-licensing-andregulatory-pathway-for-masks_September2020_vF.pdf (accessed 8 June 2021)

103. Bergwerk M, Gonen T, Lustig Y, et al. COVID-19 breakthrough infections in vaccinated healthcare workers. N Engl J Med 2021;385:1474-1484. https://doi.org/10.1056/ NEJMoa2109072

104. McAvoy M, Bui A-TN, Hansen C, et al. 3D printed frames to enable reuse and improve the fit of N95 and KN95 respirators. MedRxiv Prepr Serv Health Sci 2020. https://doi. org/10.1101/2020.07.20.20151019

105. Imbrie-Moore AM, Park MH, Zhu Y, Paulsen MJ, Wang H, Woo YJ. Quadrupling the N95 supply during the COVID-19 crisis with an innovative 3D-printed mask adaptor. Healthcare 2020;8(3):225. https://doi.org/10.3390/healthcare8030225
106. Centers for Disease Control and Prevention. Implementing filtering facepiece respirator (FFR) reuse, including reuse after decontamination, when there are known shortages of N95 respirators (updated 19 October 2020_. Centers for Disease Control and Prevention. Atlanta: CDC, 2020. https://www.cdc.gov/ coronavirus/2019-ncov/hcp/ppe-strategy/decontamination-reuse-respirators.html (accessed 30 July 2021).

107. Bergman MS, Viscusi DJ, Zhuang Z, Palmiero AJ, Powell JB, Shaffer RE. Impact of multiple consecutive donnings on filtering facepiece respirator fit. Am J Infect Control 2012;40(4):375-380. https://doi.org/10.1016/j.ajic.2011.05.003

108. Degesys NF, Wang RC, Kwan E, Fahimi J, Noble JA, Raven MC. Correlation between N95 extended use and reuse and fit failure in an emergency department. JAMA 2020;324(1):94-96. https://doi.org/10.1001/jama.2020.9843

109. Brady TM, Strauch AL, Almaguer CM, et al. Transfer of bacteriophage MS2 and fluorescein from N95 filtering facepiece respirators to hands: Measuring fomite potential. J Occup Environ Hyg 2017;14(11):898-906. https://doi.org/10.1080/154 59624.2017.1346799

110. Kielmann K, Karat AS, Zwama G, et al. Tuberculosis infection prevention and control: Why we need a whole systems approach. BMC Infect Dis Poverty 2020;9(1):56. https://doi.org/10.1186/s40249-020-00667-6

111. Van der Westhuizen H-M, Nathavitharana RR, Pillay C, Schoeman I, Ehrlich R. The high-quality health system 'revolution': Re-imagining tuberculosis infection prevention and control. J Clin Tuberc Mycobact Dis 2019;17:100118. https://doi. org/10.1016/j.jctube.2019.100118

Accepted 5 October 2021. 